\title{
Local Distance of Wheat Spike Infection by Released Clones of Gibberella zeae Disseminated from Infested Corn Residue
}

\author{
Melissa D. Keller, Department of Plant Pathology, Physiology, and Weed Science, Virginia Polytechnic Institute and \\ State University, Blacksburg 24061-0390; Katrina D. Waxman and Gary C. Bergstrom, Department of Plant Pa- \\ thology and Plant-Microbe Biology, Cornell University, Ithaca, NY, 14850; and David G. Schmale III, Department \\ of Plant Pathology, Physiology, and Weed Science, Virginia Polytechnic Institute and State University
}

\begin{abstract}
Keller, M. D., Waxman, K. D., Bergstrom, G. C., and Schmale, D. G., III. 2010. Local distance of wheat spike infection by released clones of Gibberella zeae disseminated from infested corn residue. Plant Dis. 94:1151-1155.

Knowledge of the movement of Gibberella zeae (Fusarium graminearum) from a local source of inoculum in infested cereal debris is critical to the management of Fusarium head blight (FHB) of wheat. Previous spatial dissemination and infection studies were unable to completely distinguish the contributions of released inocula from those of background inocula. Clones of G. zeae were released and recaptured in five wheat fields in New York and Virginia in 2007 and 2008. Amplified fragment length polymorphisms were used to track and unambiguously identify the released clones in heterogeneous populations of the fungus recovered from infected wheat spikes collected at $0,3,6$, and $\geq 24 \mathrm{~m}$ from small-area sources of infested corn residues. The percent recovery of the released clones decreased significantly at fairly short distances from the inoculum sources. Isolates of $G$. zeae recovered at $0,3,6$, and $\geq 24 \mathrm{~m}$ from the center of source areas shared $65,19,13$, and $5 \%$ of the genotypes of the released clones, respectively. More importantly, the incidence of spike infection attributable to released clones averaged $15,2,1$, and $<1 \%$ at $0,3,6$, and $\geq 24 \mathrm{~m}$ from source areas, respectively. Spike infection attributable to released clones decreased an average of $90 \%$ between 3 and $6 \mathrm{~m}$ from area sources of inoculum, and the spike infection potential of inocula dispersed at this range did not differ significantly from background sources. Our data suggest that FHB field experiments including a cereal debris variable should incorporate debris-free borders and interplots of at least $3 \mathrm{~m}$ and preferably $6 \mathrm{~m}$ to avoid significant interplot interference from spores originating from within-field debris.
\end{abstract}

Fusarium head blight (FHB) or scab is a devastating disease of wheat and barley in the United States, with losses exceeding \$3 billion since 1996 (23). Grain resulting from FHB infection is often contaminated with the mycotoxin deoxynivalenol (DON) (32,34). DON is an important inhibitor of protein synthesis $(26,27)$ and may render grain unfit for human or domestic animal consumption (32). The disease and associated DON contamination continue to cause economic hardships on farms and in rural communities where small grains are grown (38). The principal causal agent of FHB in North America is the fungus Gibberella zeae (Schwein.) Petch (anamorph: Fusarium graminearum) (23,34). Frequent rainfall and high relative humidity $(12,25)$ from spike emergence through anthesis

Corresponding author: D. G. Schmale III

E-mail: dschmale@vt.edu

Any opinions, findings, conclusions, or recommendations expressed in this publication are those of the authors and do not necessarily reflect the view of the United States Department of Agriculture.

Accepted for publication 7 June 2010.

doi:10.1094/PDIS-94-9-1151

(c) 2010 The American Phytopathological Society favor inoculum production on cereal debris and resulting disease development (34). Overwintered cereal debris is a significant reservoir for $G$. zeae and contributes a source of inoculum for infection of wheat and barley plants in the same field in which debris is present $(11,34,37,39)$ and in more distant fields $(21,30)$. Future strategies for managing FHB in individual wheat and barley fields should be guided by a better understanding of the movement of $G$. zeae from within-field sources of inoculum.

Both ascospores and macroconidia of $G$. zeae contribute to FHB (22), though it is generally considered that airborne ascospores play the predominant role in infection of wheat and barley florets at anthesis $(28,31)$. Rain splash may disperse macroconidia or ascospores of $G$. zeae across meter distances within wheat canopies (24), whereas airborne ascospores may be dispersed over kilometer distances from their source $(21,29,30)$. The role of local and more distant sources of inoculum to FHB infection has not been quantified definitively.

The local dissemination of G. zeae from sources of inoculum has been investigated. de Luna et al. (10) reported a 50\% decline in ascospore concentration within $18 \mathrm{~m}$ of an inoculum source and $90 \%$ within $60 \mathrm{~m}$.
Fernando et al. (13) reported a 50\% reduction in FHB within 1 to $10 \mathrm{~m}$ from the center of an inoculated plot and a $90 \%$ reduction within 5 to $22 \mathrm{~m}$ in some locations. Stack (33) reported a $50 \%$ decline in FHB within 2 to $3 \mathrm{~m}$ of a small-area source of inoculum and within 20 to $50 \mathrm{~m}$ of a large-area source of inoculum. In the spatial dissemination studies performed to date, it has not been possible to completely distinguish the contributions of released inocula from that of background inocula.

The extent to which cereal debris management by crop rotation (i.e., avoidance), tillage, or other treatment contributes to integrated management of FHB must be assessed through field experimentation. Design and interpretation of field experiments involving a cereal debris (inoculum source of $G$. zeae) management variable must consider and minimize the effects of interplot interference from spores produced on local cereal debris. Agronomic researchers typically establish wheat field plots using small experimental drills $(6 \mathrm{ft}=$ $1.8 \mathrm{~m}$ wide) or small commercial drills (10 $\mathrm{ft}=3.0 \mathrm{~m}$ wide). The results of Fernando et al. (13) suggested that the contribution of spores to wheat infection from a concentrated area source of inoculated cereal debris is diminished to background levels within a few to several meters of the local source. In order to determine whether local distance of wheat spike infection is reduced to background levels within one to two commercial drill widths (i.e., 3 to $6 \mathrm{~m}$ ) of infested corn residue, clones of G. zeae were released and recaptured in five experimental wheat fields in New York and Virginia in 2007 and 2008. A genotyping technique known as amplified fragment length polymorphism (AFLP) (35) was used to track and unambiguously identify the released clones in heterogeneous populations of the fungus recovered from infected wheat plants collected $0,3,6$, and $\geq 24$ m from small-area sources of inoculum consisting of infested corn residues. Abstracts on portions of this work have been published $(18,19)$.

\section{MATERIALS AND METHODS}

Experimental fields. Experiments were conducted in commercial wheat fields in Aurora, NY (2007 and 2008); LeRoy, NY (2008); and New Kent, VA (2007 and 2008). All fields lacked previous-season 
residues of corn or small grains known to be inoculum sources of $G$. zeae $(11,23)$. Any corn residue present within the fields would have been from two or more seasons prior to the experiments. The Aurora, NY fields were planted with the soft white winter wheat $\mathrm{cv}$. Caledonia following harvest of soybean. The LeRoy, NY field was planted with the soft red winter wheat $\mathrm{cv}$. Pioneer 25R57 following harvest of pea. New Kent, VA (2007 and 2008) fields were planted with the soft red winter wheat $\mathrm{cv}$. Pioneer 26R15 following harvest of soybean.

Inocula preparation. Four singlespored strains of G. zeae (two recovered from diseased wheat in Aurora, NY, and two recovered from diseased wheat in Riner, VA) were used in the experiments. These strains represented two of the predominant trichothecene mycotoxin genotypes of the fungus: 3-acetyl deoxynivalenol (3-ADON) and 15-acetyl deoxynivalenol (15-ADON) genotypes (16). Strains Gz_NY_TS59_3-ADON (hereafter referred to as GZNY3) and $\mathrm{Gz}_{-} \mathrm{NY}_{-}$ T1S1_15-ADON (hereafter referred to as GZNY15) were used to inoculate the New York fields, and Gz_VA_GPS13N4_3ADON (hereafter referred to as GZVA3) and Gz_VA_GPS8N12_15-ADON (hereafter referred to as GZVA15) were used to inoculate the Virginia fields. Cultures of each strain were grown for 2 weeks on quarter-strength potato dextrose agar (PDA) medium. Autoclaved corn stalk pieces (7.6 to $15.2 \mathrm{~cm}$ in length) and corn kernels were inoculated with individual strains in 4-liter plastic containers. Preinoculation, tissue dry weights per plot were $300 \mathrm{~g}$ of stalk pieces and $500 \mathrm{~g}$ of kernels. Containers were stored at ambient room temperature for approximately 6 weeks to allow colonization of corn kernels or stalk pieces.

Table 1. Nine alleles were used to identify the released clones of Gibberella zeae in heterogeneous populations of the fungus collected from infected plants in Virginia and New York

\begin{tabular}{lcc}
\hline State & Allele $^{\mathbf{a}}$ & Primers and fluorescent labels $^{\mathbf{b}}$ \\
\hline VA & 102.1 & FAM-Eco-aa+MSE-at \\
VA & 106.4 & HEX-Eco-cc+MSE-cg \\
VA & 142.6 & FAM-Eco-aa+MSE-at \\
VA & 192.4 & FAM-Eco-aa+MSE-at \\
VA & 196.2 & FAM-Eco-aa+MSE-at \\
VA & 262.7 & FAM-Eco-aa+MSE-at \\
VA & 328.8 & FAM-Eco-aa+MSE-at \\
VA & 355.6 & FAM-Eco-aa+MSE-at \\
VA & 383.9 & FAM-Eco-aa+MSE-at \\
NY & 106.3 & HEX-Eco-cc+MSE-cg \\
NY & 106.9 & HEX-Eco-cc+MSE-cg \\
NY & 126.8 & HEX-Eco-cc+MSE-cg \\
NY & 157.2 & HEX-Eco-cc+MSE-cg \\
NY & 168.7 & FAM-Eco-aa+MSE-at \\
NY & 199.9 & HEX-Eco-aa+MSE-cg \\
NY & 245.6 & FAM-Eco-aa+MSE-at \\
NY & 271.6 & FAM-Eco-aa+MSE-at \\
NY & 368.3 & HEX-Eco-aa+MSE-cg \\
\hline
\end{tabular}

${ }^{\text {a }}$ Polymorphic bands (alleles) were scored from 100 to 500 bp at a peak detection threshold intensity greater than 250

${ }^{b}$ Fluorescent labels FAM and HEX were incorporated during the final selective polymerase chain reaction amplification.

Field inoculations. In 2007, field inoculations were performed 12 May (Aurora, NY) and 19 April (New Kent, VA). In 2008, field inoculations were performed 29 April (Aurora, NY), 25 April (LeRoy, NY), and 22 March (New Kent, VA). Corn stalks or corn kernels containing individual strains of $G$. zeae were placed within replicated circular plots $1 \mathrm{~m}$ in diameter with an area of $0.79 \mathrm{~m}^{2}$. Plots were surrounded by wire cages to prevent animal tampering and wind dispersal of debris. In 2007, each of the New York and Virginia fields contained a total of 10 plots: 1 control plot of noninoculated corn kernels, 1 control plot of noninoculated corn stalk pieces, 2 plots of corn stalk pieces inoculated with GZNY3 or GZVA3, 2 plots of corn kernels inoculated with GZNY3 or GZVA3, 2 plots of corn stalk pieces inoculated with GZNY15 or GZVA15, and 2 plots of corn kernels inoculated with a GZNY15 or GZVA15. Plots were separated by $\geq 24 \mathrm{~m}$. In 2008, all of the plots contained corn stalk pieces. The two New York fields contained a total of six plots: two control plots of noninoculated corn stalk pieces, two plots of corn stalk pieces inoculated with GZNY3, and two plots of corn stalk pieces inoculated with GZNY15. The Virginia field contained a total of five plots: one control plot of nonpieces, two plots of and two plots of corn stalk pieces ir with GZVA15. All fields maintained a complete wheat canopy throughout the study. No chemical or mechanical disturbance of the field occurred.

Collection of wheat spikes and isolation of G. zeae. In 2007, wheat spikes were collected 2 July (Aurora, NY) and 22 May (New Kent, VA). In 2008, wheat spikes were collected 2 July (Aurora, NY), 1 July (LeRoy, NY), and 17 May (New Kent, VA). Collection occurred approxi-

1152 Plant Disease /Vol. 94 No. 9 mately 4 weeks after anthesis (Zadoks growth stage 85) in New York and 2 weeks after anthesis (Zadoks growth stage 77) in Virginia. Spikes were collected at random at 0 (directly above the source), 3, 6, and $\geq 24 \mathrm{~m}$ from the sources. A string was tied to a stake in the center of the plot and was used to collect wheat spikes at radii of 3 and $6 \mathrm{~m}$ circling the source. Spikes were also collected from noninoculated control plots located $\geq 24 \mathrm{~m}$ from the released sources. A total of 100 spikes was assessed for FHB infection $(2,23,34)$ for each sampling distance per plot (e.g., 100 spikes at $0 \mathrm{~m}, 100$ spikes at $3 \mathrm{~m}$, and 100 spikes at $6 \mathrm{~m}$ ) for the Aurora, NY fields; 75 spikes for each sampling distance per plot for the LeRoy, NY fields; and 55 spikes for each sampling distance per plot for the New Kent, VA fields. Following FHB assessments, the spikes were surface disinfested in a $20 \%$ bleach solution for $1 \mathrm{~min}$ and rinsed with distilled water for $1 \mathrm{~min}$. Disinfested spikes were plated onto a Fusarium-selective medium (FSM) (6) containing neomycin at $0.35 \mathrm{~g} /$ liter as described by Schmale et al. (30). Plates containing the disinfested spikes were incubated for 5 to 7 days in the laboratory at ambient room temperature. One colony of a Fusarium sp. per collected spike was subcultured to petri plates containing quarter-strength PDA. Colonies producing characteristic red or pink mycelia and containing only macroconidia characteristic of $F$. graminearum (20) were single-spored onto additional plates of quarter-strength PDA. Single-spored cultures were placed in an aqueous suspension of $20 \%$ glycerol for cryogenic storage at $-80^{\circ} \mathrm{C}$.

DNA extraction and AFLP methodology. Each single-spored isolate of G. zeae was grown in 250-ml flasks of quarterstrength potato dextrose (PD) broth on a shaker operating at $100 \mathrm{rpm}$ for 5 days at $20^{\circ} \mathrm{C}$. Mycelia were harvested from individual flasks and lyophilized for at least 12 h. Lyophilized mycelia ( 0.1 to $0.3 \mathrm{~g}$ ) were homogenized in microcentrifuge tubes containing $0.5 \mathrm{~mm}$ of zirconia or silica beads on a mini-beadbeater (Model no. 3110BX; BioSpec Products, Inc., Bartlesville, $\mathrm{OK}$ ) for $1.5 \mathrm{~min}$ at $2,500 \mathrm{rpm}$. DNA was extracted from the homogenized mycelium using Qiagen's BioSprint 15 workstation (Qiagen, Inc. USA, Valencia, CA) and the Biosprint 15 DNA Plant Kit (Qiagen, Inc. USA, Valencia, CA) following the manufacturer's protocols.

AFLPs (35) were used to genotype all of the recovered isolates of $G$. zeae from field populations. Two primer pair combinations with two selective nucleotides on each primer were used: $E c o \mathrm{R} 1+\mathrm{AA}$ labeled with $\mathrm{HEX}$, and EcoR1+CC labeled with FAM. Digestions, ligations, preamplifications, and selective amplifications were conducted following standard protocols (30). AFLPs were viewed and analyzed on an Applied Biosystems Genetic Analyzer 3130xl using the Foundation Data Collec- 
tion Software, Version 3.0. Applied Biosystems Hi-Di formamide (Model no. 4311320; Applied Biosystems, Inc., Foster City, CA) and GeneScan 500Liz size standard (Model no. 4322682; Applied Biosystems, Inc.) were added to each of the sample tubes prior to each run. GeneMarker (version 1.7; SoftGenetics, LLC, State College, PA) was used to visualize electropherograms, select markers and alleles, and compare and contrast genotypes of the isolates. Polymorphic bands (alleles) were scored from 100 to $500 \mathrm{bp}$ at a peak detection threshold intensity greater than 250 . Nine unique alleles representative of GZNY3 and GZNY15 and nine unique alleles representative of GZVA3 and
GZVA15 were selected to represent the genotypes of the released strains (Table 1). The selection of these alleles was determined by censoring initial field populations for alleles with a frequency lower than $10 \%$ or greater than $90 \%$. The presence or absence of these alleles was recorded in a binary format (allele present $=$ 1 or absent $=0$ ) for all of the isolates. Isolates were considered to be the released clones when the profiles of the 9 unique alleles were identical (Table 1).

Statistical methods. Analysis of variance was used to test for differences in the percentage of spikes infected with released clones collected at $0,3,6$, and $\geq 24 \mathrm{~m}$ from the source areas and the difference be- tween the percentage of spikes infected with released clones in plots containing 3ADON and 15-ADON genotypes. Tukey's Studentized Range test and Scheffe's test were used to test for differences in the percentage of spikes infected with released clones collected between 0 and $3 \mathrm{~m}, 0$ and $6 \mathrm{~m}$, and 0 and $\geq 24 \mathrm{~m}, 3$ and $6 \mathrm{~m}, 3$ and $\geq 24 \mathrm{~m}$, and 6 and $\geq 24 \mathrm{~m}$. Analyses were performed using PROC GLM in SAS Systems for Windows (version 9.2; SAS Institute, Cary, NC). Significance was evaluated at $P<0.05$ for all tests.

\section{RESULTS AND DISCUSSION}

Released clones were distinguished unambiguously from background isolates of

Table 2. Recovery of released clones of Gibberella zeae from wheat plants at different distances from inoculum sources ${ }^{\mathrm{a}}$

\begin{tabular}{|c|c|c|c|c|c|c|c|}
\hline $\begin{array}{l}\text { Field location, state, } \\
\text { and year }\end{array}$ & $\begin{array}{l}\text { No. of } \\
\text { plots }^{\text {b }}\end{array}$ & $\begin{array}{c}\text { Clone } \\
\text { released }^{\mathrm{c}}\end{array}$ & $\begin{array}{l}\text { Distance }(m) \text { from center } \\
\text { of released source }^{d}\end{array}$ & $\begin{array}{l}\text { Spikes infected } \\
\text { by G. zeae }(\%)^{\mathrm{e}}\end{array}$ & $\begin{array}{l}\text { Spikes infected } \\
\text { by clone }(\%)^{\mathrm{f}}\end{array}$ & $\begin{array}{l}\text { Spikes infected by } \\
\text { background }(\%)^{\mathrm{g}}\end{array}$ & $\begin{array}{c}\text { Clone recovered } \\
(\%)^{\mathrm{h}}\end{array}$ \\
\hline Aurora, NY, 2007 & 4 & GZNY3 & 0 & 4 & 1 & 3 & 14 \\
\hline Aurora, NY, 2007 & 4 & GZNY3 & 3 & 2 & 0 & 2 & 0 \\
\hline Aurora, NY, 2007 & 4 & GZNY3 & 6 & 3 & 0 & 2 & 10 \\
\hline Aurora, NY, 2007 & 4 & GZNY15 & 0 & 2 & 1 & 1 & 33 \\
\hline Aurora, NY, 2007 & 4 & GZNY15 & 3 & 3 & 0 & 3 & 0 \\
\hline Aurora, NY, 2007 & 4 & GZNY15 & 6 & 2 & 0 & 2 & 0 \\
\hline Aurora, NY, 2007 & 2 & Control & 30 & 5 & 1 & 5 & 10 \\
\hline Aurora, NY, 2008 & 2 & GZNY3 & 0 & 14 & 12 & 2 & 86 \\
\hline Aurora, NY, 2008 & 2 & GZNY3 & 3 & 4 & 1 & 3 & 25 \\
\hline Aurora, NY, 2008 & 2 & GZNY3 & 6 & 8 & 0 & 8 & 0 \\
\hline Aurora, NY, 2008 & 2 & GZNY15 & 0 & 31 & 28 & 4 & 89 \\
\hline Aurora, NY, 2008 & 2 & GZNY15 & 3 & 8 & 3 & 5 & 33 \\
\hline Aurora, NY, 2008 & 2 & GZNY15 & 6 & 7 & 2 & 5 & 23 \\
\hline Aurora, NY, 2008 & 2 & Control & 30 & 11 & 1 & 11 & 5 \\
\hline LeRoy, NY, 2008 & 2 & GZNY3 & 0 & 35 & 32 & 3 & 92 \\
\hline LeRoy, NY, 2008 & 2 & GZNY3 & 3 & 1 & 1 & 0 & 100 \\
\hline LeRoy, NY, 2008 & 2 & GZNY3 & 6 & 3 & 2 & 1 & 60 \\
\hline LeRoy, NY, 2008 & 2 & GZNY15 & 0 & 24 & 15 & 9 & 61 \\
\hline LeRoy, NY, 2008 & 2 & GZNY15 & 3 & 7 & 4 & 3 & 60 \\
\hline LeRoy, NY, 2008 & 2 & GZNY15 & 6 & 2 & 1 & 1 & 33 \\
\hline LeRoy, NY, 2008 & 2 & Control & 30 & 1 & 0 & 1 & 0 \\
\hline New Kent, VA, 2007 & 4 & GZVA3 & 0 & 35 & 18 & 17 & 51 \\
\hline New Kent, VA, 2007 & 4 & GZVA3 & 3 & 25 & 1 & 24 & 5 \\
\hline New Kent, VA, 2007 & 4 & GZVA3 & 6 & 24 & 2 & 22 & 8 \\
\hline New Kent, VA, 2007 & 4 & GZVA15 & 0 & 35 & 15 & 19 & 45 \\
\hline New Kent, VA, 2007 & 4 & GZVA15 & 3 & 23 & 1 & 23 & 2 \\
\hline New Kent, VA, 2007 & 4 & GZVA15 & 6 & 27 & 1 & 27 & 2 \\
\hline New Kent, VA, 2007 & 2 & Control & 24 & 27 & 1 & 26 & 3 \\
\hline New Kent, VA, 2008 & 2 & GZVA3 & 0 & 67 & 39 & 28 & 58 \\
\hline New Kent, VA, 2008 & 2 & GZVA3 & 3 & 10 & 4 & 6 & 36 \\
\hline New Kent, VA, 2008 & 2 & GZVA3 & 6 & 22 & 10 & 13 & 42 \\
\hline New Kent, VA, 2008 & 2 & GZVA15 & 0 & 53 & 41 & 12 & 78 \\
\hline New Kent, VA, 2008 & 2 & GZVA15 & 3 & 16 & 11 & 5 & 67 \\
\hline New Kent, VA, 2008 & 2 & GZVA15 & 6 & 5 & 3 & 3 & 50 \\
\hline New Kent, VA, 2008 & 1 & Control & 24 & 0 & 0 & 0 & 0 \\
\hline \multirow[t]{4}{*}{ Aggregate data } & 28 & All clones & 0 & 22 & 15 & 8 & 65 \\
\hline & 28 & All clones & 3 & 9 & 2 & 7 & 19 \\
\hline & 28 & All clones & 6 & 9 & 1 & 8 & 13 \\
\hline & 9 & Control & $\geq 24$ & 9 & 0 & 8 & 5 \\
\hline
\end{tabular}

${ }^{a}$ Percentages were calculated from the total number of spikes sampled or isolates collected at 0 (above the source), at 3,6 , and $\geq 24 \mathrm{~m}$ from the center of the released sources.

${ }^{b}$ Number of 1-m-diameter plots per sampling areas represented containing clonal inocula (source, $0 \mathrm{~m}$ ) or no inocula (control, $\geq 24 \mathrm{~m}$ ) separated by $24 \mathrm{~m}$ (Virginia) or $30 \mathrm{~m}$ (New York) within commercial wheat fields or number of circular sampling areas at 3 and $6 \mathrm{~m}$ from centers of source plots.

${ }^{c}$ Two clones of G. zeae were released in New York (GZNY3 and GZNY15) and two clones were released in Virginia (GZVA3 and GZVA15). Corn kernels and corn stalk pieces were infested with G. zeae in 2007; in 2008, only corn stalk pieces were infested. Control plots contained noninoculated corn stalk pieces or kernels in 2007 but only noninoculated stalk pieces in 2008 .

${ }^{\mathrm{d}}$ Spikes were collected at 0 (above the source), 3,6, and $\geq 24 \mathrm{~m}$ from the center of the released sources.

${ }^{e}$ Number of infected spikes divided by the total number of spikes collected at $0,3,6$, and $\geq 24 \mathrm{~m}$ from the center of the released sources. Isolates of $G$. zeae were recovered from 55 wheat spikes per sampling-distance in Virginia, 100 in Aurora, NY, and 75 in LeRoy, NY. Percentages rounded to integer values.

${ }^{\mathrm{f}}$ Released clones of $G$. zeae recovered from total number of wheat spikes collected. Percentages rounded to integer values.

${ }^{\mathrm{g}}$ Background isolates of $G$. zeae recovered from total number of wheat spikes collected. Percentages rounded to integer values.

${ }^{\mathrm{h}}$ Released clones of G. zeae divided by the total number of isolates recovered from spikes collected at $0,3,6$, and $\geq 24 \mathrm{~m}$ from the center of the released sources. Percentages rounded to integer values. 
G. zeae by AFLPs, an approach that has been employed successfully to monitor other plant pathogens within heterogeneous populations $(1,3,4,29,40)$. Isolates of G. zeae recovered at $0,3,6$, and $\geq 24 \mathrm{~m}$ from the center of source areas shared $65 \%$ (314/483), 19\% (35/188), 13\% (26/196), and $5 \%(3 / 63)$ of the genotypes of released clones, respectively. More importantly, the incidence of spike infection attributable to released clones averaged 15\% (314/2160), $2 \%(35 / 2160), 1 \%(26 / 2160)$, and $<1 \%$ $(3 / 715)$ at these distances (Table 2; Fig. 1). The percentage of spikes infected with the released clones varied significantly across sampling distances $(P<0.001)$. Pairwise comparisons between 0 and $3 \mathrm{~m}, 0$ and 6 $\mathrm{m}$, and 0 and $\geq 24 \mathrm{~m}$ were significantly different $(P<0.05$ for both Tukey's and Scheffe's tests) when controlling for all five fields in both years of experimentation.

Asymptomatic spikes (i.e., spikes without any visible symptoms of FHB) within individual plots ranged from 86 to $100 \%$ for Virginia. All of the wheat spikes in the New York plots were asymptomatic yet many spikes were infected, as revealed by plating of surface-disinfested spikes (Table 2). Incidence of FHB symptoms was only slightly higher above clonal source plots $(92 / 1320=7 \%)$ than control plots $(5 / 110=$ $5 \%$ ) in New Kent, VA in 2007 where moisture conditions were conducive for infection at anthesis. Despite the very low incidence of symptoms on wheat spikes from the other four experimental sites (where low moisture at anthesis did not favor in- fection), the fungus was recovered from a significant percentage of asymptomatic spikes. These spikes likely were infected post flowering and there may not have been enough time for symptoms to develop prior to spike collection. Thus, our data support the idea that FHB symptoms alone may underestimate the amount of spike infection and resulting DON contamination (7-9).

The percentage of spikes infected by background inocula (i.e., isolates other than released clones) did not differ significantly $(P=0.83)$ by sampling location (including clonal source and control plots) in any of the five wheat fields. Background inocula accounted for an average of $35 \%$ of spike infection directly above concentrated (corn stalk pieces bearing abundant perithecia) clonal inoculum sources. Because our experimental fields contained little or no residues of corn or small grains from previous-year crops, the recovered background populations of G. zeae likely originated from more distant sources outside of our fields $(14,21,29,30)$.

Epidemic populations of G. zeae from wheat in the United States contain both 3ADON and 15-ADON genotypes $(15,36)$ but recent observations suggest that the 3ADON genotype may be increasing in frequency in the Midwest (15) and Canada (36). Certain strains of the 3 -ADON genotype may be more aggressive than those of the $15-A D O N$ genotype (36). In our study, the percentage of spikes infected with the released clones did not differ significantly $(P=0.96)$ between plots containing 3ADON and 15-ADON genotypes.

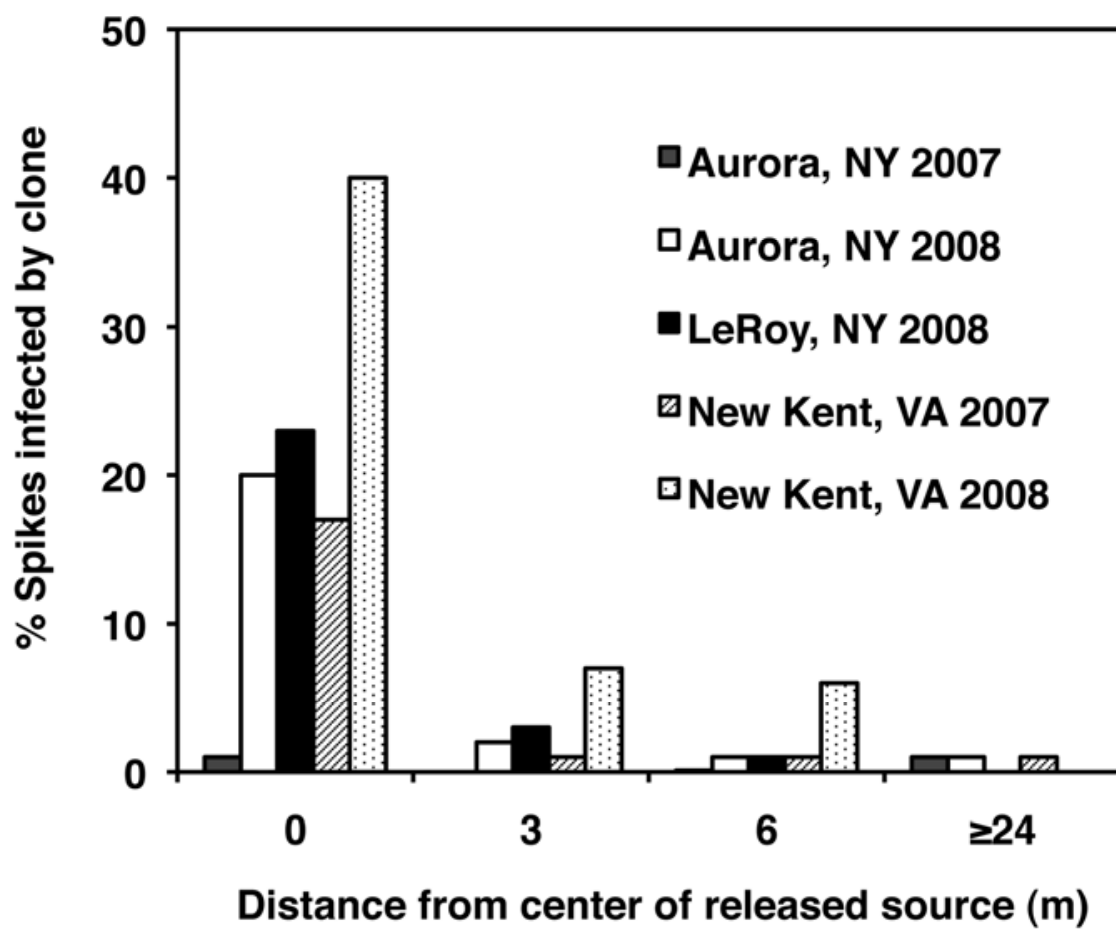

Fig. 1. Percent wheat spikes infected by locally released clones of Gibberella zeae at distances from inoculum sources for New York and Virginia in 2007 and 2008. Percentages were calculated from the total number of isolates collected at 0 (above the source), at 3,6 , and $\geq 24 \mathrm{~m}$ from the center of the released sources.
Our experimental design was spatially similar to those of Fernando et al. (13) and Stack (33) (i.e., documenting infection at distances from $1-\mathrm{m}$ diameter or $1-\mathrm{m}^{2}$ infested plots). Fernando et al. (13) reported that FHB declined by $50 \%$ at distances of 1 to $10 \mathrm{~m}$ from the inoculum sources and by $90 \%$ at distances of 10 to $25 \mathrm{~m}$, whereas Stack (33) observed a $50 \%$ decline in FHB within 2 to $3 \mathrm{~m}$ of the smallarea sources. Stack (33 and personal communication) also observed a $50 \%$ decline in spike infection within 20 to $50 \mathrm{~m}$ of a large-area $\left(30-\mathrm{m}^{2}\right)$ source of concentrated inoculum. Infection gradients from smallarea sources may be steeper than gradients from large-area sources (17). In our experiments, spike infection attributable to released clones decreased an average of $90 \%$ between 3 and $6 \mathrm{~m}$ from area sources of inoculum (Table 2), suggesting a steeper local spike infection gradient than reported by previous investigators $(13,33)$.

Studies with inoculated substrates may tend to overestimate the local contribution of natural, within-field inoculum sources compared with background sources. Release of naturally overwintered corn residues in wheat fields resulted in significantly lower levels of FHB and DON accumulation than did concentrated inoculum sources in five of six experiments in New York (5). Our data suggest that smallplot field experiments on FHB management, including a cereal debris variable, should incorporate cereal debris-free borders and interplots of at least $3 \mathrm{~m}$ and preferably $6 \mathrm{~m}$ to avoid significant interplot interference from spores originating from within-field cereal debris. Future research may identify a need for even larger cereal debris-free borders and interplots to separate research plots conducted on an agricultural field scale.

\section{ACKNOWLEDGMENTS}

This research was supported primarily by a grant ("Relative contribution of within-field inoculum to Fusarium head blight infection in wheat") from the U.S. Wheat \& Barley Scab Initiative of the United States Department of Agriculture to G. C. Bergstrom and D. G. Schmale (agreement nos. 590790-4-093 and 59-0790-7-078). Supplemental support was received from the Virginia Small Grains Board (proposal no. 07-2505-06) and Cornell University Hatch Project NYC153433. We thank P. Davis for allowing us to use his wheat fields in Virginia, D. Branton and D. Cotterill for allowing us to use their wheat fields in New York, A. Wood-Jones and L. Tamina for excellent technical assistance, and two anonymous reviewers for their constructive comments on this manuscript.

\section{LITERATURE CITED}

1. Akinsanmi, O. A., Backhouse, D., Simpfendorfer, S., and Chakraborty, S. 2006. Genetic diversity of Australian Fusarium graminearum and $F$. pseudograminearum. Plant Pathol. 55:494-504.

2. Bai, G., and Shaner, G. 1994. Scab of wheat: prospects for control. Plant Dis. 78:760-766.

3. Bayon, C., Pei, M. H., Ruiz, C., Hunter, T., Karp, A., and Tubby, I. 2009. Genetic structure and population dynamics of a heteroecious plant pathogen Melampsora larici-epitea in 
short-rotation coppice willow plantations. Mol. Ecol. 18:3006-3019.

4. Bennett, R. S., Milgroom, M. G., Sainudiin, R., Cunfer, B. M., and Bergstrom, G. C. 2007. Relative contribution of seed-transmitted inoculum to foliar populations of Phaeosphaeria nodorum. Phytopathology 97:584-591.

5. Bergstrom, G. C., and Waxman, K. D. 2008. Microplots in commercial wheat fields for quantifying the local contribution of Gibberella zeae from natural corn debris to Fusarium head blight and deoxynivalenol accumulation. Pages 6-8 in: Proc. 2008 Natl. Fusarium Head Blight Forum, Indianapolis, IN.

6. Burgess, L. W., Summerell, B. A., Bullock, S., Gott, K. P., and Backhouse, D. 1994. Laboratory Manual for Fusarium Research, 3rd ed. University of Sydney, Australia.

7. Cowger, C., Patton-Özkurt, J., Brown-Guedira, G., and Perugini, L. 2009. Post-anthesis moisture increased Fusarium head blight and deoxynivalenol levels in North Carolina winter wheat. Phytopathology 99:320-327.

8. Cowger, C., and Sutton, A. L. 2005. The southeastern U.S. Fusarium head blight epidemic of 2003. Published Online. Plant Health Progress DOI:10.1094/PHP-2005-1026-01-RS.

9. Del Ponte, E. M., Fernandes, J. M. C., and Bergstrom, G. C. 2007. Influence of growth stage on Fusarium head blight and deoxynivalenol production in wheat. J. Phytopathol. 155:577-581.

10. de Luna, L., Bujold, I., Carisse, O., and Paulitz, T. C. 2002. Ascospore gradients of Gibberella zeae from overwintered inoculum in wheat fields. Can. J. Plant Pathol. 24:457-464.

11. Dill-Macky, R., and Jones, R. K. 2000. The effect of previous crop residues and tillage on Fusarium head blight of wheat. Plant Dis. 84:71-76.

12. Fernando, W. G. D., Miller, J. D., Seaman, W. L., Seifert, K., and Paulitz, T. C. 2000. Daily and seasonal dynamics of airborne spores of Fusarium graminearum and other Fusarium species sampled over wheat plots. Can. J. Bot. 78:497-505.

13. Fernando, W. G. D., Paulitz, T. C., Seaman, W. L., Dutilleul, P., and Miller, J. D. 1997. Head blight gradients caused by Gibberella zeae from area sources of inoculum in wheat field plots. Phytopathology 87:414-421.

14. Francl, L., Shaner, G., Bergstrom, G, Gilbert, J., Pedersen, W., Dill-Macky, R., Sweets, L., Corwin, B., Jin, Y., Gallenberg, D., and Wiersma, J. 1999. Daily inoculum levels of Gibberella zeae on wheat spikes. Plant Dis. 83:662-666.
15. Gale, L. R., Ward, T. J., Balmas, V., and Kistler, H. C. 2007. Population subdivision of Fusarium graminearum sensu stricto in the upper Midwestern United States. Phytopathology 97:1434-1439.

16. Goswami, R. S., and Kistler, H. C. 2004. Heading for disaster: Fusarium graminearum on cereal crops. Mol. Plant Pathol. 5:515-525.

17. Gregory, P. H. 1968. Interpreting plant disease dispersal gradients. Annu. Rev. Phytopathol. 6:189-212.

18. Keller, M. D., Duttweiler, K. D., Schmale, D. G., and Bergstrom, G. C. 2007. Contribution of within-field inoculum sources to Fusarium head blight in wheat. Page 98 in: Proc. 2007 Natl. Fusarium Head Blight Forum, Kansas City, MO.

19. Keller, M. D., Schmale, D. G., Waxman, K. D., and Bergstrom, G. C. 2008. Released clones and background inocula of Gibberella zeae contributed to Fusarium head blight in winter cereals in New York and Virginia. Page 37 in: Proc. 2008 Natl. Fusarium Head Blight Forum, Indianapolis, IN

20. Leslie, J. F., and Summerell, B. A. 2006. The Fusarium Laboratory Manual. Blackwell Publishing.

21. Maldonado-Ramirez, S. L., Schmale, D. G., Shields, E. J., and Bergstrom, G. C. 2005. The relative abundance of viable spores of Gibberella zeae in the planetary boundary layer suggests the role of long-distance transport in regional epidemics of Fusarium head blight. Agric. For. Meteorol. 132:20-27.

22. Markell, S. G., and Francl, L. J. 2003. Fusarium head blight inoculum: species prevalence and Gibberella zeae spore type. Plant Dis. 87:814-820.

23. McMullen, M. P., Jones, R., and Gallenberg, D. 1997. Scab of wheat and barley: a reemerging disease of devastating impact. Plant Dis. 81:1340-1348.

24. Paul , P. A., El-Allaf, S. M., Lipps, P. E., and Madden, L. V. 2004. Rain splash dispersal of Gibberella zeae within wheat canopies in Ohio. Phytopathology 94:1342-1349.

25. Paulitz, T. C. 1996. Diurnal release of ascospores by Gibberella zeae in inoculated wheat plots. Plant Dis. 80:674-678.

26. Pestka, J. J. 2007. Deoxynivalenol: toxicity, mechanisms and animal health risks. Anim. Feed Sci. Technol. 137:283-298.

27. Pestka, J. J, and Smolinski, A. T. 2005. Deoxynivalenol: toxicology and potential effects on humans. J. Toxicol. Environ. Health B Crit. Rev. 8:39-69.

28. Schmale, D. G., and Bergstrom, G. C. 2003.
Fusarium head blight. The Plant Health Instructor. DOI:10.1094/PHI-I-2003-0612-01.

29. Schmale, D. G., III, Leslie, J. F., Zeller, K. A., Saleh, A. A., Shields, E. J., and Bergstrom, G. C. 2006. Genetic structure of atmospheric populations of Gibberella zeae. Phytopathology 96:1021-1026.

30. Schmale, D. G., III, Shields, E. J., and Bergstrom, G. C. 2006. Night-time spore deposition of the Fusarium head blight pathogen, Gibberella zeae. Can. J. Plant Pathol. 28:100-108.

31. Shaner, G. E. 2003. Epidemiology of Fusarium head blight of small grain cereals in North America. Pages 84-119 in: Fusarium Head Blight of Wheat and Barley. K. J. Leonard and W. Bushnell, eds. American Phytopathological Society, St. Paul, MN.

32. Snijders, C. H. A. 1990. Fusarium head blight and mycotoxin contamination of wheat, a review. Neth. J. Plant Pathol. 96:187-198.

33. Stack, R. W. 1997. Gradients of Fusarium head blight in wheat along transects away from a concentrated source of Gibberella zeae ascospore inoculum. Page 60 in Proc. Nationa Fusarium Head Blight Forum, St. Paul, MN

34. Sutton, J. C. 1982. Epidemiology of wheat head blight and maize ear rot caused by Fusarium graminearum. Can. J. Pathol. 4:195-209.

35. Vos, P., Hogers, R., Bleeker, M., Reijans, M. van de Lee, T., Hornes, M., Frijters, A., Pot, J. Peleman, J., Kuiper, M., and Zabeau, M. 1995. AFLP: a new technique for DNA fingerprinting. Nucleic Acids Res. 23:4407-4414.

36. Ward, T. J., Clear, R. M., Rooney, A. P., O'Donnell, K., Gaba, D., Patrick, S., Starkey, D. E., Gilbert, J., Geiser, D. M., and Nowicki, T. W. 2008. An adaptive evolutionary shift in Fusarium head blight pathogen populations is driving the rapid spread of more toxigenic Fusarium graminearum in North America. Fungal Genet. Biol. 45:473-484

37. Wiese, M. V. 1987. Compendium of Wheat Diseases, 2nd ed. American Phytopathological Society, St. Paul, MN

38. Windels, C. E. 2000. Economic and social impacts of Fusarium head blight: changing farms and rural communities in the northern Great Plains. Phytopathology 90:17-21.

39. Windels, C. E., and Kommedahl, T. 1984. Late-season colonization and survival of Fusarium graminearum group II in cornstalks in Minnesota. Plant Dis. 68:791-793.

40. Zeller, K. A., Bowden, R. L., and Leslie, J. F. 2003. Diversity of epidemic populations of Gibberella zeae from small quadrats in Kansas and North Dakota. Phytopathology 93:874-880. 